\title{
Long term trends of waste generation
}

\author{
U. Bardi \& A. Lavacchi \\ Dipartimento di Chimica, Università di Firenze, \\ 50019 Sesto Fiorentino (Fi), Italy
}

\begin{abstract}
Despite the large number of studies on the many facets of waste management, only a modest activity seems to have been expended on the question of forecasting trends of waste generation and, in particular, worldwide long term trends. In planning, the public and administrators alike always seem to assume that the rate of waste generation will continue its historical trend of increase. Yet, this expectation does not seem to be based on models or on factual studies. The first system dynamics study of worldwide waste production was reported in 1973 and, already at that time, a slowdown and, eventually, a decrease of the rate of waste production was the long term expectation from the model. Examining the present worldwide situation, we see that indeed such a slowdown, and even a trend reversal is ongoing in several countries. It appears that the waste generation rate will not keep increasing forever.
\end{abstract}

Keywords: waste management, dynamic modelling.

\section{Introduction}

The historical trend of increase in waste generation worldwide has been fuelling worries about how to manage this large flux of materials. At times, the future is described as an environmental catastrophe in which waste will engulf us all as a consequence of the filling up of the available landfills. Something not unlike this extreme scenario has been taking place in Naples, Italy, in 2008.

But nothing can grow forever in a finite world and waste generation cannot be an exception. Yet, forecasting waste generation trends is not commonly seen in the reports of the various waste management agencies in the world and is not common in the scientific literature, either. In this sense, the waste management industry is much different than its equivalent at the opposite end of the industrial cycle: the extractive industry and in particular the fossil fuels industry. The latter 
is notoriously very concerned (one might say "obsessed") with forecasting production trends even over several decades in the future (see, e.g., the reports by the International Energy Agency, IEA [2]). In this paper we will examine waste generation trends using methods borrowed from those used in forecasting petroleum production. In particular, we'll use a simple model derived from assumptions similar to those of the well known "Hubbert model" [3, 4].

The first model study of waste generation is probably the one reported by Randers and Meadows in 1973 [1]. The study was based on a system dynamics model that took into account the whole industrial cycle, starting with the availability of limited amounts of raw materials. The result was that waste generation would eventually peak and decline together with the peaking and declining of the worldwide production of energy and raw materials. Although a number of studies on waste generation were performed using system dynamics (see, e.g., ref [5]), to our knowledge, no study after the one by Randers and Meadows took into account the complete industrial system. Today, 35 years after that pioneer study, we see that the scenarios outlined in that early study turn out to be correct. Waste generation may not have peaked yet worldwide, but the generation rate is clearly declining while several individual countries have peaked. Waste production, it seems, will mirror the expected productive trends of mineral resources, peaking and declining in a not too remote future.

\section{Experimental data}

We'll examine here mostly municipal solid waste (MSW) as the kind of waste that generates the highest degree of concern among public and administrators

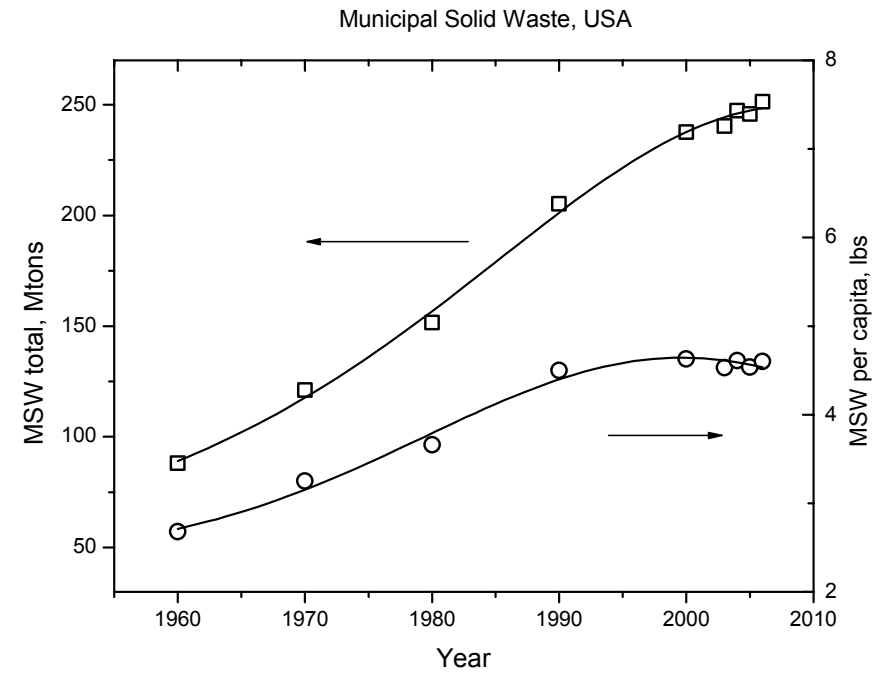

Figure 1: Generation of municipal solid waste in the US. Data from EPA [6]. The experimental data have been fitted using the derivative of a logistic function. 
alike. It is also the kind of waste for which the most detailed and comprehensive data seem to exist. We start with the data for the United States [6].

The data have been fitted with the derivative of a logistic function; the justification for the use of this function will be discussed in the next section. The overall MSW generation in the US is still increasing, but the amount of MSW generated per person appears to have peaked around the year 2000 and is slowly decreasing.

For Europe, data have been obtained from EUROSTAT [7]. In this case, the time series available are more limited: only from 1995. Nevertheless, the data show that the overall European trend for MSW generation is similar to that of the US. Both the total waste production and the waste produced per person appear to be in decline for the EU-27 region.

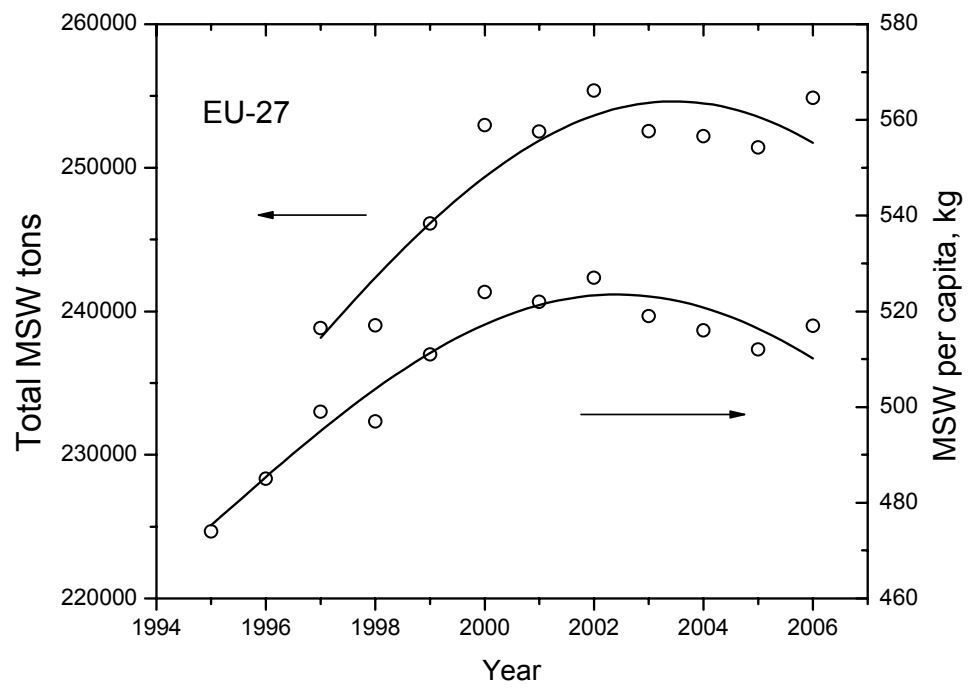

Figure 2: Data for MSW generation for the EU-27 area. The per capita MSW are from EUROSTAT [7]; the total MSW was obtained multiplying the per capita data times the population, also from EUROSTAT data.

There are several individual European countries that have also peaked in terms of total municipal waste generation. Among these are Belgium, the Netherlands and Poland. Others, in contrast, still show an increasing trend in waste generation, both in the total amount and in the amount per capita. This is the case, for instance, of Italy. In general, the overall trend in the western world seems to be one of declining growth rates of waste generation and, in several cases of an actual decline in waste generation.

A possible interpretation of the trend is that what we are seeing is a change in the waste composition. That is, urban solid waste could contain, for instance, more plastic rather than metals or building materials. This is a complex matter, 
but it seems clear that it cannot account for the trends we see. In the US, the fraction of plastics in urban waste has been increasing during the past decades at the expense of the "humid" organic fraction. But this trend is tapering off [9] and in any case it hardly explains the slowdown of the total weight of waste since plastics and organic waste are not much different in terms of density. In Europe, the trend seems to be opposite; at least in Italy, we see a reduction of the fraction of plastics in urban waste [10]. Again, the trend is not sufficiently large to explain the observed effects in waste generation.

Another possible interpretation of the trend is that policies and laws set by the various governments are causing the reduction of waste generation. That doesn't seem to be the case, either. Mostly, governmental policies tend to deal with waste collection and disposal, but rarely have interfered, so far, with the actual processes that generate waste. There have been some attempts to regulate what is called "overpackaging" and there exists an EC directive on this point [11]. But the directive seems to be aimed mainly at recovering and recycling packaging material rather than reducing its production.

The interpretation that we propose here is that the economy is an engine. With less fuel in input, it will produce less "exhaust" (waste) as output. It appears that the production of fossil fuels is slowing down, with signs of a possible global peak of crude oil ("peak oil") in the near future $[4,13]$. The reduced supply of oil may be causing a slowdown in the production of several minerals [14]. In turn, this reduced supply of minerals and energy should be mirrored at the other extreme of the cycle, in terms of waste generation.

If this interpretation is correct, we should also see the effect not only at the tailpipe, but also within the engine itself. That is, we should also see a reduction of the industrial production, matching the reduction in waste generation. The problem here is that a direct comparison is not possible since industrial production and waste generation are normally measured in different units. A measure of the output of an economy is the gross domestic product (GDP), which can be disaggregated in terms of GDP related to industrial production only. The industrial GDP for the US and for most industrialized countries is increasing. The problem is that the GDP is measured in monetary units. It measures the value of the products generated, but not their weight when these products appear as waste in the statistical data. Industrial production refers also to entities, such as computer software, which produce GDP but that have no mass and therefore generate no weighable waste.

More relevant to what we are discussing is here is the "industrial production index" as reported, for instance, by the Federal Reserve for the US [12]. The index measures real goods production, excluding services and most "non material" goods. However, the IP index is, again, not measured in physical units but it is an index obtained summing up the physical outputs of the various industries weighted from their proportion in the total value-added output of all industries. In other words, the production of a semiconductor chip (high added value) counts more in the index than that of a potato chip (low added value).

The IP index curves for the whole manufacturing sector don't show any clear evidence of a bell shaped tendency for the US or Japan, although they may for 
Italy. However, we do see such a tendency in the US if we exclude the high technology industries. We may assume that these data for industrial production are for "traditional" industries and therefore are roughly proportional to the mass produced.

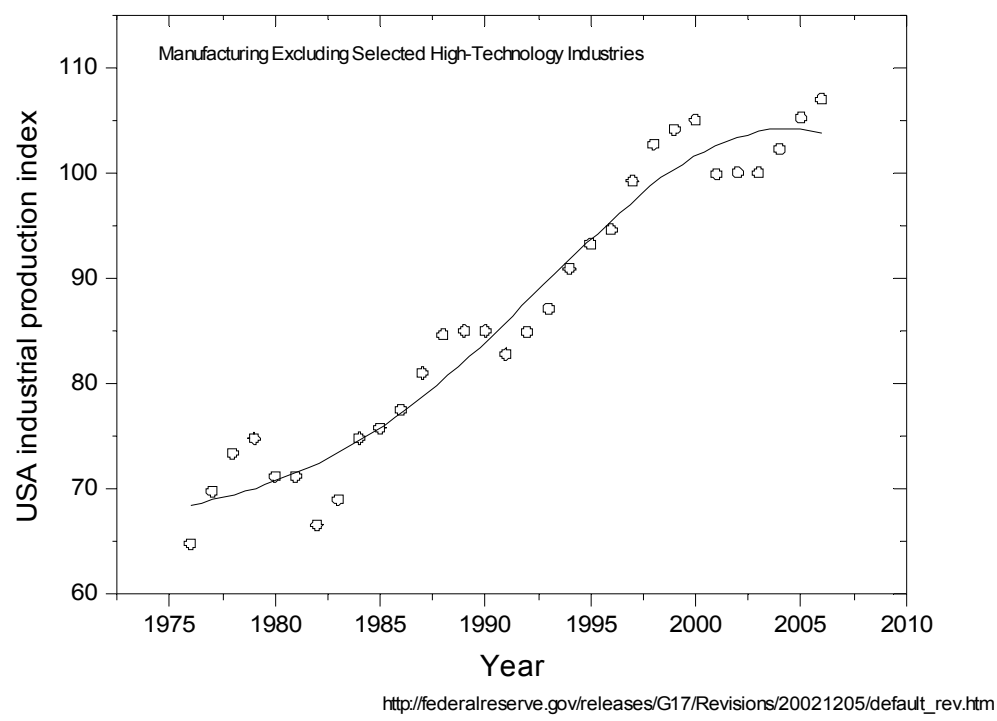

Figure 3: Industrial production index for the US, excluding selected high technology industries [10].

The fact that we see a peak of production in recent years may be telling us that the industry is getting smarter, producing higher added value items but a lower total mass. So, the data seem to match and do indicate that the production system of industrialized countries is processing less mass and using less energy. Therefore, it appears that we have here the reason for the slowing down rate of waste generation.

\section{Models}

The first dynamic model describing waste generation was reported by Randers and Meadows in 1973 [1]. The model took into account the whole waste generation system and it was schematized as follows by the authors:

The actual model utilized by Randers and Meadows is complex and it takes into account feedback phenomena among its elements. In particular, the model assumes that the cost of extraction of natural resources increases with depletion (negative feedback loop) and from this it assumes that the cost of raw materials will gradually increase. This effect affects industrial production forcing the system to reduce production and recycle raw materials. The model was 
implemented according to different scenarios. If no specific measures are taken to curb waste generation, a "robust" result of all runs is that the waste generation curve is "bell shaped", that is, it tends to peak and then decline. It appears that the real world has followed the path outlined by these scenarios.

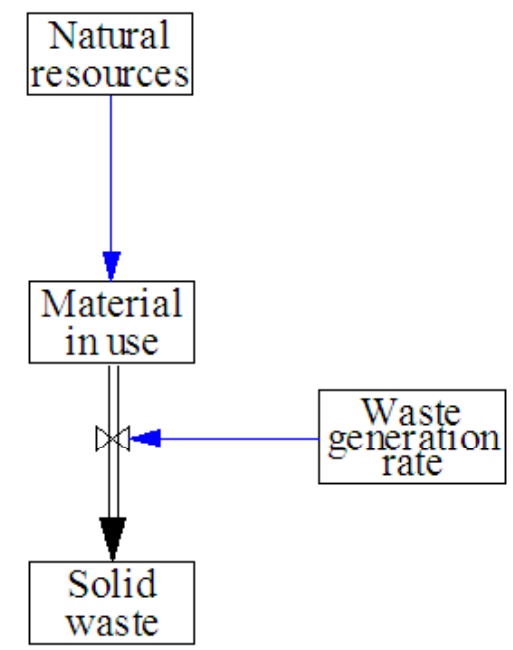

Figure 4: Schematic representation of the system dynamics model proposed by Randers and Meadows. Redrawn from [1].

We have developed a new version of the Randers-Meadows model that we will discuss elsewhere. In the present paper, we wish to discuss a simple interpretation that justifies the empirical finding of a "bell shaped" curve for waste generation. The basis of the model lies in the concept that waste generation is proportional to the industrial activity in the economic system. We assume also that the industrial activity is inversely proportional to the cost of raw materials; in turn assumed to be proportional to the depletion of a fixed initial stock. If we further assume that the ratio of waste generation to industrial production remains the same throughout the cycle (no recycling and no technological improvement of efficiency) then we can derive the following balance differential equation:

$$
\frac{d M}{d t}=r M\left(1-\frac{M}{K}\right)
$$

where $M$ is the overall amount of produced waste at a given time $t, r$ and $K$ are constants. The equation assumes that waste generation $(d M / d t)$ is proportional to industrial production. The latter is expressed as waste generation multiplied by the constant $(r)$ defining the waste fraction generated by production. Waste generation $(d M / d t)$ is also negatively proportional to the amount of waste generated; the latter term is correlated to the finite amount of raw material stock. $K$, in this case, is the asymptotic limit for waste generation and it corresponds to the total amount of waste created at the completion of the production cycle. 
When $K=M$, waste generation goes to zero as the initial stock of natural resources has been exhausted.

The equation derived here is known as Verhulst's law since it was first derived by Verhulst in population dynamics as a correction of the Malthus model, which predicts an infinite exponential growth. It admits an analytical solution as follows:

$$
M(t)=\frac{K M_{o} e^{r t}}{K+M_{o}\left(e^{r t}-1\right)}
$$

where $\mathrm{M}_{\mathrm{o}}$ is the amount of the produced waste at the starting time. Introducing the parameter $\mathrm{q}$ defined as:

$$
q=\frac{K-M_{o}}{M_{o}}
$$

and substituting q in Eq. (3) we get Eq. (4)

$$
M(t)=\frac{K}{1+q e^{-r t}}
$$

which is also known as the "logistic curve". Its plot against time provides the sigmoid with the asymptotic limit $\mathrm{K}$. Waste generation is then the first derivative of the logistic curve, namely the second member of the Verhulst equation (Eq. (1)) and originates the bell shaped curve.

These considerations explain how it is possible to fit the experimental trends of waste generation by means of a simple bell curve. It is, obviously, an approximation that doesn't take into account such factors as recycling or technological improvements. It is, however, sufficiently close to reality to permit a good fitting. In this sense, the logistic fitting of the waste generation trend is equivalent to the well known "Hubbert model" used for forecasting oil production [3, 4]. The Hubbert model doesn't explicitly take into account such factors as technological improvements and market prices but it is nevertheless a robust model that has been demonstrated many times to have predictive capabilities [13].

\section{Conclusions}

The results presented here are still tentative and are based on a limited set of data. More work would be needed for a general assessment of waste generation trends worldwide and not only for municipal solid waste. Nevertheless, the experimental data and the models developed here concord in showing that a worldwide peak in waste generation is expected in the future and that several regions of the world may have already passed it for municipal solid waste. The trend is even more evident if we consider waste generation per capita. It seems that there exists a good correlation of what happens at the two ends of the economic process chain. At the input side, the slowdown of oil production affects the production of all raw materials and this trend is reflected at the other end, the output, where we see the same slowdown of the production of waste.

This result contrasts with the common assumption in everyday practice of waste management that sees waste as an ever increasing (or at least for the 
foreseeable future) flow of materials. In a way, "peak waste" is a welcome trend, because we are used to refer to waste as a problem, often as a difficult and intractable one. The emergency in waste management that some regions of the world are experiencing may be a temporary event, destined to recede in the near future as the waste generation rate starts receding. This doesn't mean that good waste management practices are not necessary, but that the situation may be much less dramatic than it is sometimes presented. Therefore, solutions to the waste problem need not to be developed in excessive haste.

\section{References}

[1] Randers, J. and Meadows, D.L. "The Dynamics of Solid Waste Generation" in "Towards Global Equilibrium: Collected Papers", Meadows, Dennis L. and Meadows, Donella H. Cambridge, MA 1973

[2] www.iea.org

[3] Hubbert, M.K. (1982). Techniques of Prediction as Applied to Production of Oil and Gas, US Department of Commerce, NBS Special Publication 631, May 1982

[4] Campbell, C.J. and Laherrère, J. H., Scientific American, March 1998

[5] Dyson, B., Chang, NB "Forecasting municipal solid waste generation in a fast-growing urban region with system dynamics modeling. Waste Management 25 (2005) 669-679

[6] EPA 2008 Municipal Solid Waste Generation, Recycling, and Disposal in the United States: Facts and Figures for 2006 http://www.epa.gov/ epaoswer/non-hw/muncpl/pubs/msw06.pdf

[7] http:// ec.europa.eu/eurostat

[8] www.apat.it

[9] Environmental Protection Agency (EPA) "Municipal Solid Waste in the United States, 2005, http://www.epa.gov/epaoswer/non-hw/muncpl/ pubs/mswchar05.pdf

[10] Lostrangio D., Pandolfo, R." Influence of the qualitative-quantitative evolution of the municipal solid waste management". Ambiente e diritto, 2006, http://www.ambientediritto.it/dottrina/Politiche $\% 20$ energetiche $\% 20$ ambientali/politiche\%20e.a/influenza_evoluzione_lostrangio_pandolfo.htm

[11] EC 1994 EC Directive on Packaging and Packaging Waste (94/62/EC), http://ec.europa.eu/environment/waste/packaging index.htm

[12] Federal Reserve, 2008, http://federalreserve.gov/releases/G17/Revisions/ Current/default_rev.htm

[13] Zittel Werner, Schindler Jorg (2007-10). Crude Oil: The Supply Outlook. Energy Watch Group.

[14] Bardi U., Pagani M., "Peak Minerals", October 15, 2007, “The Oil Drum" http://europe.theoildrum.com/node/3086 